\title{
MONITORING PESTICIDES DEGRADATION IN APPLE FRUITS AND POTENTIAL EFFECTS OF RESIDUES ON HUMAN HEALTH
}

\author{
Manuela Olga Pogăcean ${ }^{\mathrm{a}}$, Raluca Maria Hlihor ${ }^{\mathrm{b}}$, Maria Gavrilescu ${ }^{\mathrm{b}, \mathrm{c}}$ \\ ${ }^{a}$ Plant Protection Agency Mureş, 80 Dezrobirii Street, Tîrgu Mureş, Romania \\ ${ }^{b}$ Faculty of Chemical Engineering and Environmental Protection, Deparment of Environmental Engineering \\ and Management, „Gheorghe Asachi” Technical University of Iaşi, \\ 73 Prof. Dr. Docent D. Mangeron, 700050 Iasi, Romania \\ 'Academy of Romanian Scientists, 54 Splaiul Independentei, 050094 Bucharest, Romania
}

Submitted 27 Apr. 2013; accepted 28 Jan. 2014

\begin{abstract}
The behaviour of 12 pesticides used in the treatment of a variety of apples in areal conditions from a Romanian orchard is studied, considering recommended dosages, different stages of fruit development, environmental and atmospheric conditions. Five treatments were applied in recommended dosage considering the phenological growth phases, at 23 days intervals between treatments. Pesticides degraded quickly in apples during the first days, when $30-50 \%$ from the initial concentration is lost. Pesticides residues at harvesting were below the Maximum Residue Level (MRL) in European Union, excepting tebuconazole and chlorothalonil. The estimated lifetime exposure dose was calculated based on pesticide concentrations in apples at harvesting, and average fruit consumption of $197.08 \mathrm{~g} /$ person/day in EU-27 during 2011. These doses for adults and children were below the reference dose (RfD) for each pesticide, suggesting a negligible risks for consumers. Hazard indices below 1 demonstrate that the studied pesticides do not generate health risks to humans.
\end{abstract}

Keywords: degradation, pesticides, Maximum Residue Level, phenological phases, human health risk assessment.

\section{Introduction}

Pesticides are used on a large scale to control the diseases and the pests from agricultural cultures, but they can leave residuals in the food products. The level of these residues is rigorously regulated and monitored due to the potential risks that the pesticides can cause to the people's health (Zhang et al. 2007). Consequently, food safety is a major public concern worldwide.

Since fruits and vegetables represent a major part of the human diet contributing with nutrients and vitamins, researches regarding the risks associated with consumption of food contaminated with pesticides have increased in the last decade. The total dietary intake of pesticides residues in fruits and vegetables could affect the consumers particularly when these products are preferred in a fresh form (Zawiyah et al. 2007).

Since ingestion represents the main exposure route, the exposure to pesticide residues through the diet is considered to be five orders of magnitude higher than other exposure routes, such as air or drinking water (Juraske et al. 2009). Increasing the pesticide dosages with the purpose of obtaining safe results to fight with diseases and pests in apples can have adverse effects, including the accumulation of large amounts of residuals in products (Preda et al. 2012; Van Klaveren, Boon 2009).

According to the World Health Organization, food consumption consists on an average of $30 \%$ (based on mass) of fruit and vegetables (WHO 2003). Furthermore, since these products are usually consumed uncooked or semi-processed, it is expected to contain higher pesticide residues levels compared to other food groups of plant origin, such as foodstuffs based on cereal processing (Claeys et al. 2011; Dragus et al. 2012).

The understanding of the pesticides degradation in relation with other factors and the determination of pesticide residues is very important not only for the correct assessment of the food risks, but also for the optimization

Corresponding author: Maria Gavrilescu

E-mail: mgav@ch.tuiasi.ro; mgav_ro@yahoo.com 
of the pesticides applying techniques in order to create an efficient management (Mocanu et al. 2012). Keeping under control the diseases and the pests during fruits growth requires multiple treatments based on soot, insecticides and acaricides, most of the times at an interval of 8-10 days all along the season (Schirra et al. 2011; Williamson et al. 2008).

Many studies have been done in order to investigate the pesticide residues on different cultures with respect to the physiological and physical factors in laboratory or on field conditions and of storage (Barriada-Pereira et al. 2005; Deng et al. 2010; Fernàndez-Cruz et al. 2006; Mansour et al. 2009), but few have been focused on studying the content of pesticide residues in phenological phases of development (Gericke et al. 2010; Tixier et al. 2007). Considering these aspects, previous studies were concentrated especially on the retention time and on the pesticide residues from leaves (Xu et al. 2008).

Pesticide residues in fruits and vegetables must fall below the Maximum Residue Level (MRL). In Europe, Regulation (EC) No. 396/2005 modified by Regulations (EC) No. 839/2008 and No. 459/2010 of the European Parliament and Council, respectively, set the MRL of pesticides in plant and animal products (Table 1) (Salghi et al. 2012; Zawiyah et al. 2007).

To fulfil the requirements of these regulations, EU Member States use to perform official controls to assure the conformity of food samples with concern to the pesticide MRL legislation. There are two control programmes in each European reporting country: 1) a national control/monitoring programme (designed individually by each country); and 2) a European coordinated multiannual control programme, which gives clear guidance on which specific control activities should be performed by the Member States. The EU-coordinated programme aims to provide statistically representative data regarding pesticide residues in food available to European consumers. The results acquired in the coordinated programme allow an estimation of the actual consumer exposure, being considered an indicator for the MRL in food of plant and animal origin placed on the European common market (EFSA 2013).

Monitoring the pesticide residues in apples is part of every quality evaluation and the determination of pesticide residues in fruits and vegetables has as main objective the prevention of any possible risk to human health (Kurz et al. 2008; Osman et al. 2010). Several analytical methods can be used in pesticide determination, such as high performance liquid chromatography coupled to a mass spectrometer (LC-MS) and gas chromatography mass spectrometer (GC-MS), gas chromatograph (GC) equipped with an electron capture detector (ECD) (Dragus et al. 2012; Weinberg, Teodosiu 2012; Soceanu et al. 2012).
This paper discusses the results gathered during the monitoring of concentration dynamics for common pesticides applied in treatments performed on Jonathan apples in an orchard located in Mures County - the centre of Romania. The evaluation of their degradation in time was performed starting from the recommended dosage, in different stages of fruit growth. The results allowed the estimation of the potential human health risks associated with the pesticide residues. Six fungicides that belong to the phthalimide chemical group, derivatives of the benzene and phenol, triazoles and imidazoles (captan, folpet, myclobutanil, tebuconazole, chlorolothalonil and triadimenol), five insecticides, pyrethroids of synthesis, organophosphorus of contact and ingestion (bifenthrin, deltamethrin, alpha-cypermethrin, lambda-cypermethrin, chlorpyrifos-methyl) and one acaricide (propargite) were used in the study. Pesticide residues were analysed in apples along with various stages of fruits development in order to determine if there are any quantifiable amounts of the degraded pesticides in time, and if the loss rates are influenced by temperature, relative humidity and precipitations, in the conditions of a temperate continental climate characterized by low thermal values, a shorter vegetation period, long and sunny autumns.

\section{Materials and methods}

\subsection{Chemicals and solvents}

The analytical standards were obtained from Chem Service (West Chester, SUA) and Sigma Aldrich Laborchemikalien $\mathrm{GmbH}$ (Seelze, Germany) always with the purity certified between $95.1 \%$ and $99.7 \%$. Acetone, petroleum ether, dichloromethane, toluene and isooctane were Super Purity Solvents from Fluka \& Riedel-de Haën (Sigma-Aldrich, UK). Distilled water used was provided by a Thermo Scientific TKA system (Niederelbert Germany). All samples were stored in a refrigerator at $4{ }^{\circ} \mathrm{C}$ until further use. The standard solutions were dissolved in toluene and later stored in a refrigerator at $4{ }^{\circ} \mathrm{C}$. The pesticide products used in the study were purchased from Dafcochim SRL (Tg. Mures, Romania) and Chemark Rom SRL (Tg. Mures, Romania) and are presented in Table 1.

\subsection{Gas chromatography - mass spectrometry analysis}

The pesticide residues were analyzed by a gas chromatograph (Agilent 7890 type with 2 ovens) coupled with a mass spectrometer with flight time, $\mathrm{CG}^{*} \mathrm{GC}-\mathrm{TOF}-$ MS Pegasus 4.21 (LECO, SUA). The conditions for gas chromatography analysis were: capillary column Rxi-Ms $(30 \mathrm{~m} \cdot 0.25 \mathrm{~mm} \cdot 0.25 \mu \mathrm{m})$ as main oven and BPX-50 $(1.6 \mathrm{~m} \cdot 0.1 \mathrm{~mm} \cdot 0.1 \mu \mathrm{m})$ as secondary oven. The carrier gas and make-up gas was helium at a flow rate of $1.0 \mathrm{~mL} /$ $\min$. The injector temperature was set at $250^{\circ} \mathrm{C}$. The oven 
temperature was programmed as follows: main oven, $70{ }^{\circ} \mathrm{C}$ hold for $1 \mathrm{~min}$, ramp at $20^{\circ} \mathrm{C} / \mathrm{min}$ to $140^{\circ} \mathrm{C}$, hold for $1 \mathrm{~min}$, ramp at $5{ }^{\circ} \mathrm{C} / \mathrm{min}$ to $310^{\circ} \mathrm{C}$, hold for $4 \mathrm{~min}$; secondary oven, $95^{\circ} \mathrm{C}$ hold for $1 \mathrm{~min}$, ramp at $20^{\circ} \mathrm{C} / \mathrm{min}$ to $165^{\circ} \mathrm{C}$, hold for $1 \mathrm{~min}$, ramp at $5^{\circ} \mathrm{C} / \mathrm{min}$ to $330^{\circ} \mathrm{C}$, hold for $4 \mathrm{~min}$. The injection volume of the $\mathrm{GC}$ was $1.0 \mu \mathrm{L}$. The conditions used for the mass spectrometer analysis were: ion source temperature, $220^{\circ} \mathrm{C}$, ionization mode EI, $70 \mathrm{eV}$, detector Voltage 1800, Start mass 40, End start 450, Acquisition Rate ${ }^{*}$ spectre/second, 5, temperature of transfer, $280^{\circ} \mathrm{C}$ and time of analysis, $43 \mathrm{~min}$. The high-performance auto sampler software enables the syringe washing with several solvents (at least four different solvents in the same washing phase) to end the contamination (Pogăcean et al. 2013). The major ions $(\mathrm{m} / \mathrm{z})$ and retention time $\left(t_{R}\right)$ were considered for pesticide identification (Table 2 ).

\subsection{Experimental}

A number of 5 treatments have been done at the recommended dosage by manufacturers of commercial pesticides (Table 1) in an orchard of Jonathan apples, situated within the Mureş Phytosanitary Unit (Romania), according to the phenological phases, for fruit sizes of 20-25 mm, 30-40 mm, 1/2 of normal size fruit, $2 / 3$ of normal size fruit and at ripening for a naturally-coloured fruit, with a time of 23 days between treatments. The
$\mathrm{BBCH}$ scale (Biologische Bundesanstalt, Bundessortenamt and CHemical industry), a system for a uniform coding of phenologically-similar growth stages of all mono- and dicotyledonous plant species has been taken into account and is presented in Table 3 according to each size of the fruit (Meier et al. 2001).

A buffer zone was ensured between the apples subjected to the experiment. Samples were taken after 2, 5 and 15 days, after the application of the treatment, for each of the fruits stages, during the period 30.05.201129.08.2011, at harvest and 2 months after harvest. Figure 1 shows the chromatogram of pesticides found in a sample of Jonathan apple. Chlorothalonil degradation curves and mass spectra for a sample analysed, for the phenological stage of 30-40 mm fruit size after 2, 5 and 15 days, and the mass spectrum of chlorothalonil are shown in Figure 2. $250 \mathrm{~g}$ of whole fruits picked from different areas of the trees (by randomization) were cut in quarters and mixed at a speed of 6,000 rpm for $1.5 \mathrm{~min}$. From the mixed sample, $15 \pm 0.15 \mathrm{~g}$ were weighed. For the extraction procedure dichloro-methane, acetone and petrol ether were used as solvents.

The vial which contained the sample and the solvents was blended in an ultraturax shaker at 15,000 rpm for $1 \mathrm{~min}$. After this, the vial was introduced into a multicuva centrifuge and centrifuged at 4,000 rpm for $10 \mathrm{~min}$. In order to ensure an advanced homogenization of the

Table 1. Commercial name of products, doses, and $\mathrm{MRL}^{\star}$ of targeted pesticides

\begin{tabular}{|c|c|c|c|c|}
\hline Products commercial names & Active substance & Group & $\begin{array}{l}\text { Recommended } \\
\text { dose }(\%)\end{array}$ & $\begin{array}{c}\text { MRL } \\
(\mathrm{mg} / \mathrm{kg})\end{array}$ \\
\hline $\begin{array}{l}\text { Merpan } 80 \text { WDG } \\
\text { (grains dispersible in water) }\end{array}$ & $\begin{array}{l}\text { captan } \\
80 \%\end{array}$ & Phthalimide & 0.15 & $<3$ \\
\hline $\begin{array}{l}\text { Shavit F } 72 \text { WDG } \\
\text { (grains dispersible in water) }\end{array}$ & $\begin{array}{l}\text { folpet } 70 \%+ \\
\text { triadimenol } 2 \%\end{array}$ & $\begin{array}{l}\text { Phthalimide } \\
\text { Triazole }\end{array}$ & 0.2 & $\begin{array}{l}<3 \\
0.2\end{array}$ \\
\hline $\begin{array}{l}\text { Systhane } 12 \mathrm{E} \\
\text { (emulsifiable concentrate) }\end{array}$ & $\begin{array}{l}\text { myclobutanil } \\
125 \mathrm{~g} / \mathrm{L}\end{array}$ & Triazole & 0.04 & $<0.5$ \\
\hline $\begin{array}{l}\text { Bravo } 500 \text { SC } \\
\text { (concentrated suspension) }\end{array}$ & $\begin{array}{l}\text { chlorothalonil } \\
500 \mathrm{~g} / \mathrm{L}\end{array}$ & Chloronitrile & 0.25 & $<1$ \\
\hline $\begin{array}{l}\text { Folicur Solo } 250 \mathrm{EW} \\
\text { (emulsion - oil in water) }\end{array}$ & $\begin{array}{l}\text { tebuconazole } \\
250 \mathrm{~g} / \mathrm{L}\end{array}$ & Triazole & 0.05 & $<1$ \\
\hline $\begin{array}{l}\text { Reldan } 40 \text { EC } \\
\text { (emulsifiable concentrate) }\end{array}$ & $\begin{array}{l}\text { chlorpyrifos-methyl } \\
400 \mathrm{~g} / \mathrm{L}\end{array}$ & Organophosphate & 0.15 & $<0.5$ \\
\hline $\begin{array}{l}\text { Seizer } 10 \text { EC } \\
\text { (emulsifiable concentrate) }\end{array}$ & $\begin{array}{l}\text { bifenthrin } \\
100 \mathrm{~g} / \mathrm{L}\end{array}$ & Pyrethroids & 0.05 & $<0.3$ \\
\hline $\begin{array}{l}\text { Fastac } 10 \text { EC } \\
\text { (emulsifiable concentrate) }\end{array}$ & $\begin{array}{l}\text { alpha-cypermetrin } \\
100 \mathrm{~g} / \mathrm{L}\end{array}$ & Pyrethroids & 0.02 & $<0.2$ \\
\hline $\begin{array}{l}\text { Karate Zeon } \\
\text { (concentrated suspension) }\end{array}$ & $\begin{array}{l}\text { lambda-cyhalothrin } \\
50 \mathrm{~g} / \mathrm{L}\end{array}$ & Pyrethroids & 0.015 & $<0.1$ \\
\hline $\begin{array}{l}\text { Decis } 2,5 \mathrm{EC} \\
\text { (emulsifiable concentrate) }\end{array}$ & $\begin{array}{l}\text { deltamethrin } \\
25 \mathrm{~g} / \mathrm{L}\end{array}$ & Pyrethroids & 0.05 & $<0.2$ \\
\hline $\begin{array}{l}\text { Omite } 570 \text { EW } \\
\text { (emulsion - oil in water) }\end{array}$ & $\begin{array}{l}\text { propargite } \\
570 \mathrm{~g} / \mathrm{L}\end{array}$ & Sulfite ester & 0.1 & $<3$ \\
\hline
\end{tabular}

${ }^{\star} \mathrm{MRL}$ - Maximum Residue Level set by European Union legislation (https://secure.pesticides.gov.uk/MRLs) 
Table 2. Pesticides identification based on GCxGC-TOF MS conditions

\begin{tabular}{|c|c|c|c|c|c|c|}
\hline Pesticides & IUPAC Name & Formula & Use & $\begin{array}{l}\text { Molecular } \\
\text { weight } \\
(\mathrm{g} / \mathrm{mol}) \\
\end{array}$ & $\begin{array}{c}\mathrm{t}_{\mathrm{R}} \\
(\mathrm{min})\end{array}$ & $\begin{array}{l}\text { MS Selected } \\
\text { ions }(\mathrm{m} / \mathrm{z})\end{array}$ \\
\hline Captan & $\begin{array}{l}\text { N(trichloromethylthio)cyclohex- } \\
\text { 4-ene-1,2 dicarboximide }\end{array}$ & & Fungicide & 300.6 & 26.03 & $\begin{array}{l}117,149 \\
264\end{array}$ \\
\hline Folpet & $\begin{array}{l}\mathrm{N}[\text { (trichloromethyl)thio }] \\
\text { phtalimide }\end{array}$ & & Fungicide & 296.6 & 26.25 & $\begin{array}{l}104,260 \\
262\end{array}$ \\
\hline Triadimenol & $\begin{array}{l}\text { (1RS,2RS;1RS,2SR)-1-(4- } \\
\text { chlorophenoxy)-3,3-dimethyl-1- } \\
\text { (1H-1,2,4-triazol-1-yl)butan-2-ol }\end{array}$ & & Fungicide & 295.8 & 25.68 & $\begin{array}{l}112,128 \\
168\end{array}$ \\
\hline Myclobutanil & $\begin{array}{l}\text { (RS)-2-(4-chlorophenyl)-2-(1H- } \\
\text { 1,2,4-triazol-1-ylmethyl) } \\
\text { hexanenitrile }\end{array}$ & & Fungicide & 288.8 & 27.73 & $\begin{array}{l}179,181 \\
245\end{array}$ \\
\hline Chlorothalonil & Tetrachloroisophtalonitrile & & Fungicide & 265.9 & 20.58 & $\begin{array}{c}109,264 \\
268\end{array}$ \\
\hline Tebuconazole & $\begin{array}{l}\text { (RS)-1-p-chlorophenyl-4,4- } \\
\text { dimethyl-3-(1H-1,2,4-triazol-1- } \\
\text { ylmethyl)pentan-3-ol }\end{array}$ & & Fungicide & 307.8 & 31.06 & $\begin{array}{l}125,250 \\
\quad 252\end{array}$ \\
\hline $\begin{array}{l}\text { Chlorpyrifos- } \\
\text { methyl }\end{array}$ & $\begin{array}{l}\text { O,O-dimethyl-O-3,5,6-trichloro- } \\
\text { 2-pyridylphosphorothioate }\end{array}$ & & Insecticide & 322.5 & 21.83 & $\begin{array}{l}\text { 125. } 286 \\
288\end{array}$ \\
\hline Bifenthrin & $\begin{array}{l}\text { 2-methylbiphenyl-3-ylmethyl } \\
\text { (1RS)-cis-3-[(Z)-2-chloro- } \\
\text { 3,3,3-trifluoroprop-1-enyl]-2,2- } \\
\text { dimethylcyclopropanecarboxylate }\end{array}$ & & Insecticide & 422.8 & 31.83 & $\begin{array}{c}165,181 \\
182\end{array}$ \\
\hline $\begin{array}{l}\text { Alpha- } \\
\text { cypermethrin }\end{array}$ & $\begin{array}{l}\text { (1RS,3RS;1RS,3SR)-3- } \\
\text { (2,2-Dichlorovinyl)-2,2- } \\
\text { dimethylcyclopropane-1- } \\
\text { carboxylate }\end{array}$ & & Insecticide & 415.3 & 37.53 & $\begin{array}{l}127,163 \\
165\end{array}$ \\
\hline \multirow{2}{*}{$\begin{array}{l}\text { Lambda- } \\
\text { cyhalothrin }\end{array}$} & $\begin{array}{l}\text { (S)-alpha-cyano-3- } \\
\text { phenoxybenzyl (Z)-(1R,3R)-3-(2- } \\
\text { chloro-3,3,3-trifluoropropenyl)- } \\
\text { 2,2-dimethylcyclopropane- } \\
\text { carboxylate }\end{array}$ & & \multirow[t]{2}{*}{ Insecticide } & 449.9 & 33.78 & $\begin{array}{c}141,181 \\
208\end{array}$ \\
\hline & $\begin{array}{l}\text { (R)-alpha-cyano-3- } \\
\text { phenoxybenzyl (Z)-(1S,3S)-3-(2- } \\
\text { chloro-3,3,3-trifluoropropenyl)- } \\
\text { 2,2-dimethylcyclopropane- } \\
\text { carboxylate }\end{array}$ & & & 505.2 & 40.53 & $\begin{array}{l}172,181 \\
\quad 253\end{array}$ \\
\hline Deltamethrin & $\begin{array}{l}\text { S)-alpha-cyano-3- } \\
\text { phenoxybenzyl) (1R,3R)- } \\
\text { 3-(2,2-dibromovinyl)-2,2- } \\
\text { dimethylcyclopropane } \\
\text { carboxylate }\end{array}$ & & Insecticide & 350.5 & 30.92 & $\begin{array}{l}135,173 \\
350\end{array}$ \\
\hline Propargite & $\begin{array}{l}\text { (1RS,2RS;1RS,2SR)-2-(4-tert- } \\
\text { butylphenoxy)cyclohexyl prop-2- } \\
\text { ynyl sulfite }\end{array}$ & & Acaricide & 300.6 & 26.03 & $\begin{array}{c}117,149 \\
264\end{array}$ \\
\hline
\end{tabular}


sample, $15 \mathrm{~mL}$ were pipetted into a Heidolph balloon of $100 \mathrm{~mL}$ and then attached to a Heidolph rotoevaporator coupled with a vacuum pump at a rotation of the balloon at $120 \mathrm{rpm}$ until dryness. After the solvent evaporation, the sample was redissolved in $3 \mathrm{~mL}$ mixture of isooctane: toluene $(9: 1 \mathrm{v} / \mathrm{v})$ containing $0.2 \mathrm{mg} / \mathrm{L}$ internal standard (hexachlorobenzene, HCB), sonicated for 3-5 minutes, at room temperature and then analysed through the GC-MS (modified Mini-Luke method, EURL-FV 2010). The temperature, the precipitations and the humidity were monitored by a weather station within the Mureş Phytosanitary Unit (Romania).

\subsection{Human health risk estimation}

The exposure assessment for human health risk estimation was made based on the evaluation of pesticides concentrations in apples at harvest. Food consumption data are an essential component of risk assessment and were based on the newest edition of "Freshfel Consumption Monitor", which analyses trends in the production, trade and supply of fresh fruits and vegetables across the EU-27. Specifically, the per capita fruit consumption in 2011 stands at $197.08 \mathrm{~g} /$ person/day on average for the EU-27 (FRESHFEL 2013). The estimated lifetime exposure dose ( $\mathrm{mg} / \mathrm{kg} /$ day), food consumption ( $\mathrm{kg} /$ person/ day) and body weight ( $\mathrm{kg}$ ) were used to determine if there are any health risks to consumers posed by pesticide residues in apples.
Table 3. Phenological growth stage and identification keys of the fruit

\begin{tabular}{cclc}
\hline No & $\begin{array}{c}\text { BBCH } \\
\text { stage }\end{array}$ & \multicolumn{1}{c}{$\begin{array}{c}\text { Fruit description/ } \\
\text { size }\end{array}$} & $\begin{array}{c}\text { Pesticides } \\
\text { application date }\end{array}$ \\
\hline 1 & $72-73$ & $20-25 \mathrm{~mm}$ & 30.05 .2011 \\
2 & 74 & $30-40 \mathrm{~mm}$ & 22.06 .2011 \\
3 & 75 & $1 / 2$ normal size & 15.072011 \\
4 & $76-79$ & $2 / 3$ normal size & 7.08 .2011 \\
5 & $81-85$ & at ripening & 29.08 .2011 \\
6 & $91-99$ & at harvest & - \\
7 & - & 2 months after harvest & - \\
\hline
\end{tabular}

Based on food consumption rate for fruits in Europe, the estimated lifetime exposure dose ( $\mathrm{mg} / \mathrm{kg} /$ day) was obtained by multiplying the residual pesticide concentration $(\mathrm{mg} / \mathrm{kg})$ in the apple samples with the food consumption rate ( $\mathrm{kg} /$ person/day), and dividing the product by the body weight $(\mathrm{kg})$. The toxicological significance of apples consumer exposure to pesticides is also addressed through a comparison of exposure estimates with toxicological endpoints such as Reference Dose (RfD). For some of the pesticides identified in apple samples when RfDs values are not assessed, the analogous to RfD, Acceptable Daily Intake (ADI) values, were used as substitutes. Both RfD and ADI were derived from lists compiled by the U.S. Environmental Protection Agency. The RfD for chronic oral exposure and ADI values estimate the largest amount of a chemical to which a person can be exposed on a daily

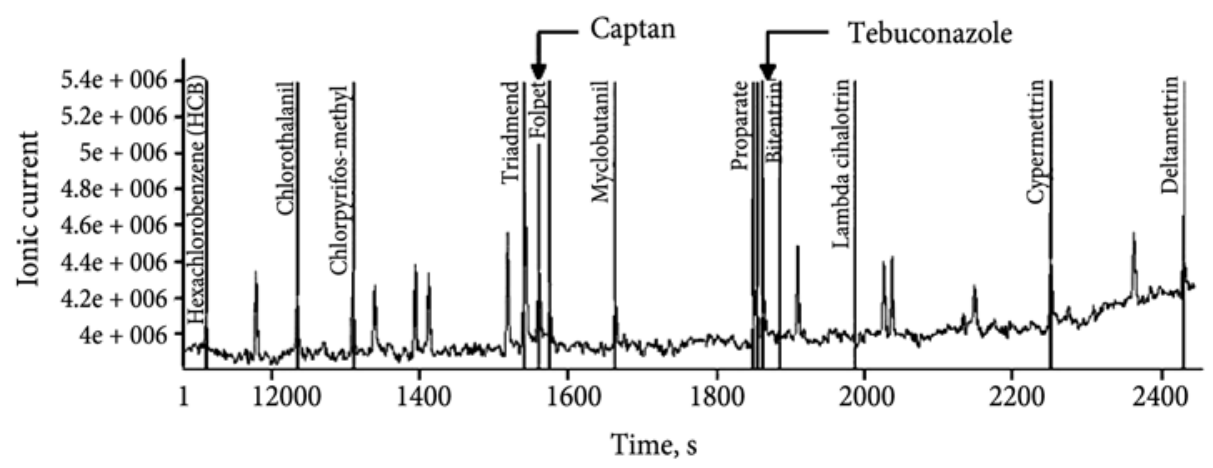

Fig. 1. GC ${ }^{\star}$ GC-FOF-MS separation of mixture of pesticides found in the sample of Jonathan apples

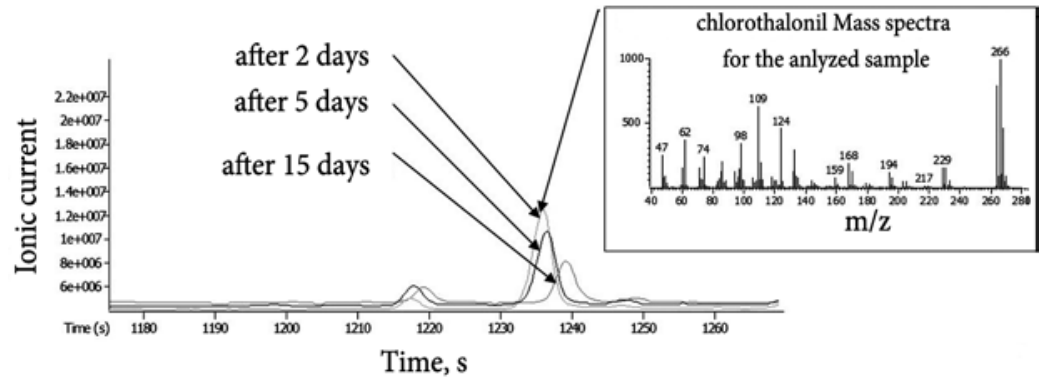

Fig. 2. Chromatogram of chlorothalonil degradation in apples after 2, 5 and 15 days for the phenological stage $30-40 \mathrm{~mm}$ fruit size $(\mathrm{BBCH} 74)$ 
basis that is not anticipated to result in adverse effects (Tucker 2008; USEPA 2011, 2013; Winter, Katz 2011). The next hypotheses were made considering the U.S Environmental Protection Agency's guidelines: 1) maximum absorption rate is $100 \%$; and 2) bioavailability rate is $100 \%$ (Akoto et al. 2013; Bempah et al. 2011; USEPA 2011). The average body weight of adults in Europe was estimated as $70.8 \mathrm{~kg}$ (Walpole et al. 2012) and as $31.8 \mathrm{~kg}$ for children (age group, 6 to $<11$ years, USEPA 2011).

In order to assess a more accurately human health risk estimation of pesticide residues from Jonathan apples, the hazard indices (HI) for adults and children were evaluated as the ratio between estimated pesticide exposure doses and the corresponding RfDs (Bempah et al. 2011; Hlihor et al. 2009; Reinhold, Tint 2010). The food involved is considered either a risk to consumers if $\mathrm{HI}>1$, either acceptable if $\mathrm{HI}<1$ (Akoto et al. 2013; Pogăcean et al. 2013).

\section{Results and discussions}

\subsection{Pesticides degradation in apples}

The degradation of the analysed pesticides in different phenological growth stages (Meier et al. 2001) of apples is influenced by weather conditions, especially by temperature (Fig. 3), relative humidity (Fig. 4), and precipitations (Fig. 5). Temperature has an important role in the volatilization of the active substances. This is connected to the tension of vaporization specific to the compound (De Schampheleire et al. 2009). Pesticides which contain active substances such as, chlorpyrifos-methyl, deltamethrin and alpha-cypermethrin have a higher potential of volatilization than other pesticides studied, therefore they have a higher volatilization tendency. In Figure 3 it can be observed that the average temperatures in the period 22.06.2011-07.07.2011, were between $13.5^{\circ} \mathrm{C}$ and $25^{\circ} \mathrm{C}$, the thermal regime being lower compared with

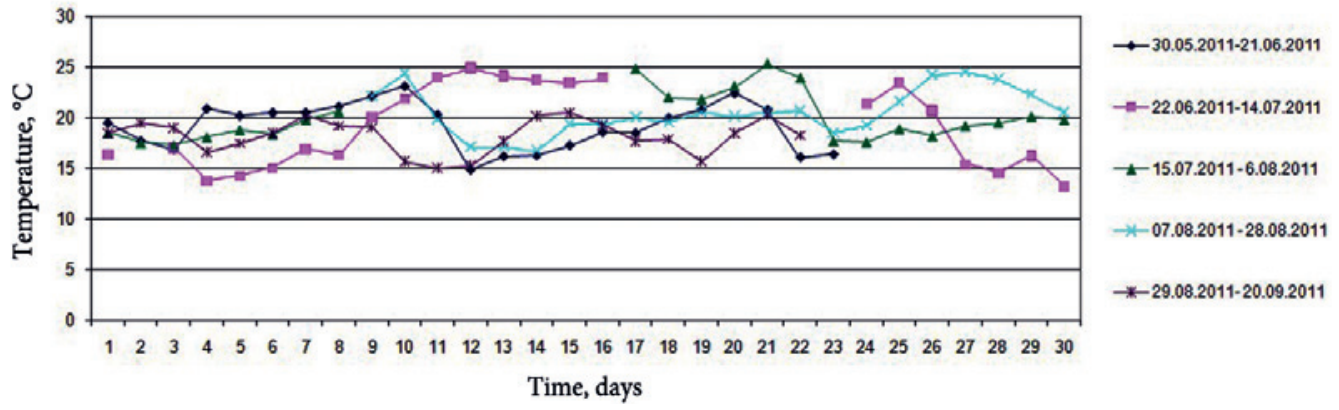

Fig. 3. Variation of temperature along the duration of the phenological phases

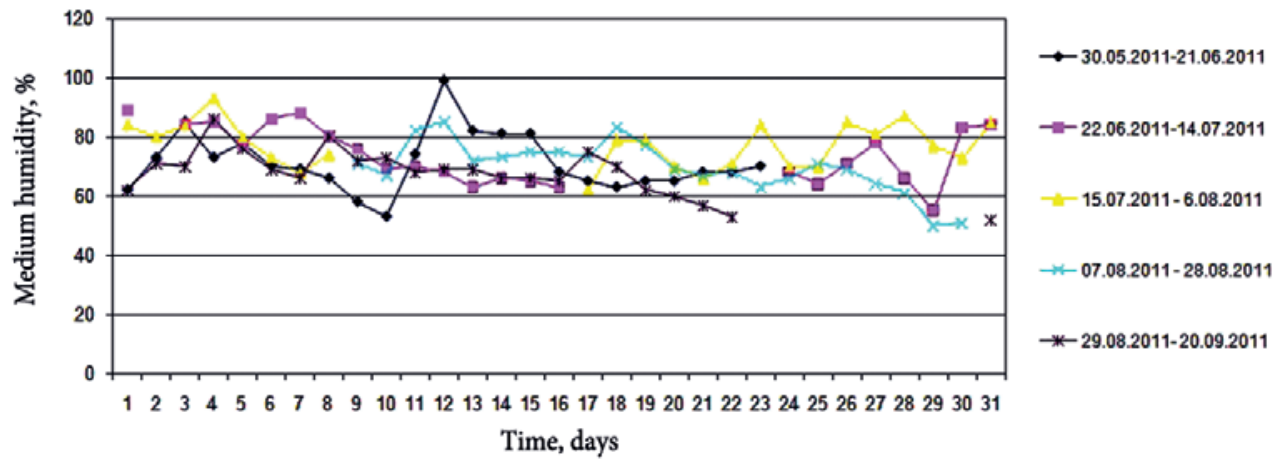

Fig. 4. Variation of medium humidity along the duration of the phenological phases
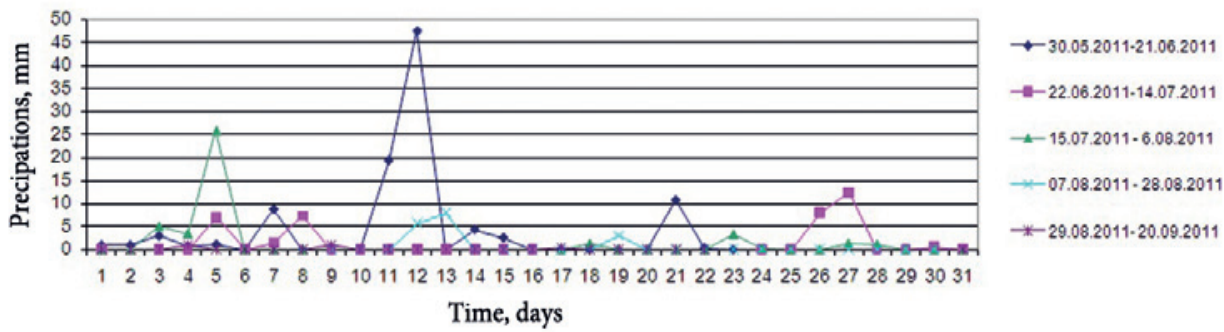

Fig. 5. Variation of precipitations along the duration of the phenological phases 
other periods of the study. The relative humidity of the air (Fig. 4) contributes to the increase of the pesticides persistence in fruits as it favourites their absorption and also facilitates the volatilization (Abhilash, Singh 2009).

The volume of precipitations was significantly higher in two periods of the study, 30.05.2011-14.06.2011 and 22.06.2011-07.07.2011 (Fig. 5), affecting particularly the degradation of the pesticides folpet and captan (Xu et al. 2008). In our case, it was found that the precipitations strongly influence the content of pesticide residues, especially if they interfere in the first 24 hours after the application of the pesticides. It seems that the volume of precipitations is far more important than their intensity in terms of washing the substances concentrated on plants (Abhilash, Singh 2009). Such a situation was observed during 22.06.2011-07.07.2011, when residual pesticides content resulted below the MRL, after 15 days following the treatment of plants with fruit having a size of $30-40 \mathrm{~mm}$ (BBCH 74). This behaviour was noticed for the active substances such as folpet (Fig. 8), captan (Fig. 10), bifenthrin (Fig. 11), chlorpyrifos-methyl (Fig. 13), alpha-cypermethrin (Fig. 14) and triadimenol (Fig. 17), compared with other periods of time mentioned in the study, when the precipitations were lower (7.08.2011-27.08.2011).

The concentration of chlorothalonil residuals after 5 days following the application of the treatment is with 45-50\% smaller than the concentration measured after two days from the application.

Furthermore, in 15 days after the application of the treatment for each phenological phase, it was observed that the concentration of chlorothalonil residuals is much higher than the MRL. The values of chlorothalonil residuals in the phenological phase of 20-25 mm (BBCH 72-73) are much higher compared with other phenological stages (BBCH 74, BBCH 75, BBCH 76-79, BBCH 81-85).

Therefore, the fruits dimension (and therefore their age) influences the content of residuals: smaller/younger fruit holds a higher quantity of chlorothalonil. The degradation curves of chlorothalonil decreased after 2 days, 5 days and 15 days. The analyses performed in 2 months after harvest, showed that a concentration of chlorothalonil residuals of $0.49 \mathrm{mg} / \mathrm{kg}$ was found, below the MRL of $1 \mathrm{mg} / \mathrm{kg}$ (Fig. 6).

The content of myclobutanil residuals drops significantly below MRL after 15 days from the application of the treatment in the stages of fruit development of 20-25 mm (BBCH 72-73), 30-40 mm (BBCH 74) and $1 / 2$ of normal size fruit (BBCH 75) (Fig. 7), being heavily influenced by the large amount of precipitations (Fig. 5). During the harvesting period (BBCH 91-99) and two months after, the residuals concentration was of $0.1 \mathrm{mg} / \mathrm{kg}$ and $0.07 \mathrm{mg} /$ $\mathrm{kg}$ respectively, below the MRL $(0.5 \mathrm{mg} / \mathrm{kg})$.

The degradation of the folpet is influenced by humidity and by the volume of precipitations, especially during 15 days after the treatment application. This behaviour was

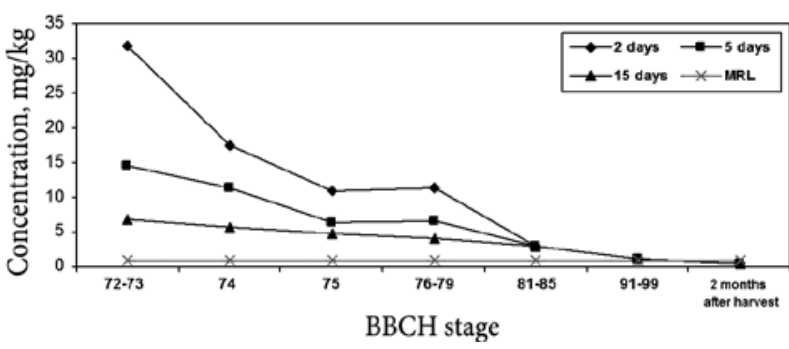

Fig. 6. Degradation of chlorothalonil in Jonathan apples

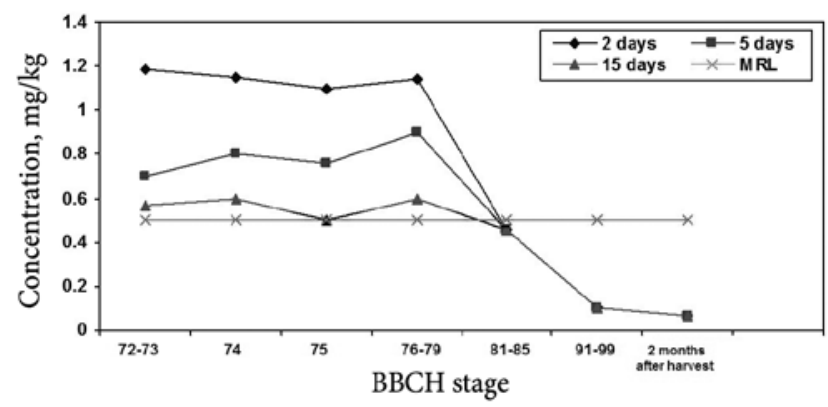

Fig. 7. Degradation of myclobutanil in Jonathan apples

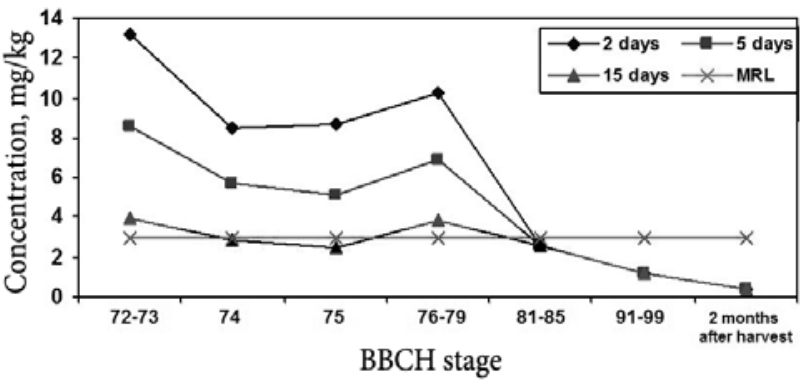

Fig. 8. Degradation of folpet in Jonathan apples

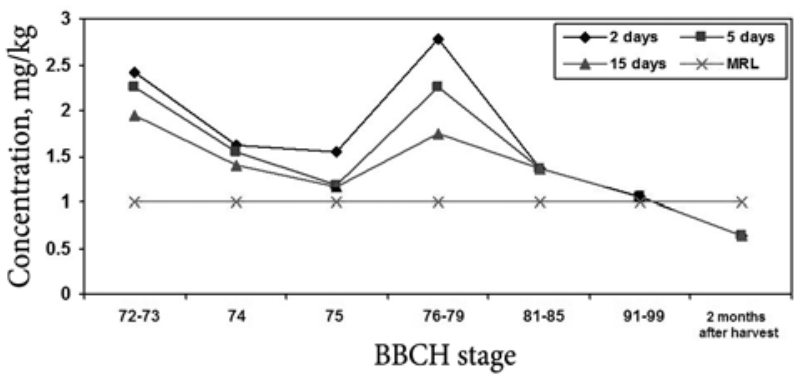

Fig. 9. Degradation of tebuconazole in Jonathan apples

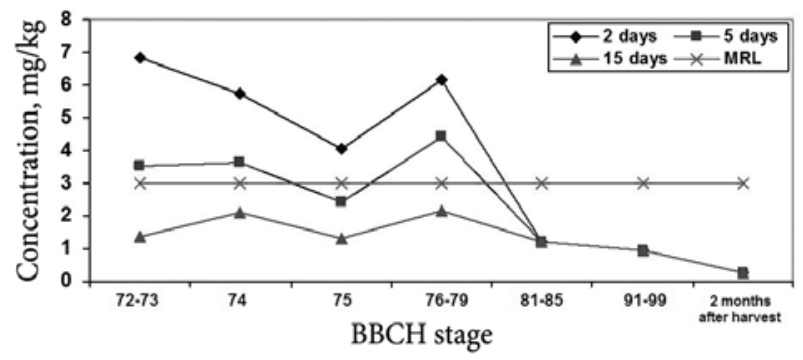

Fig. 10. Degradation of captan in Jonathan apples 


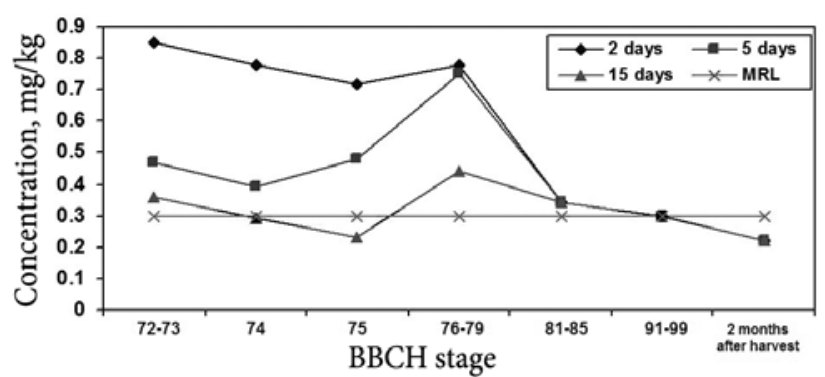

Fig. 11. Degradation of bifenthrin in Jonathan apples

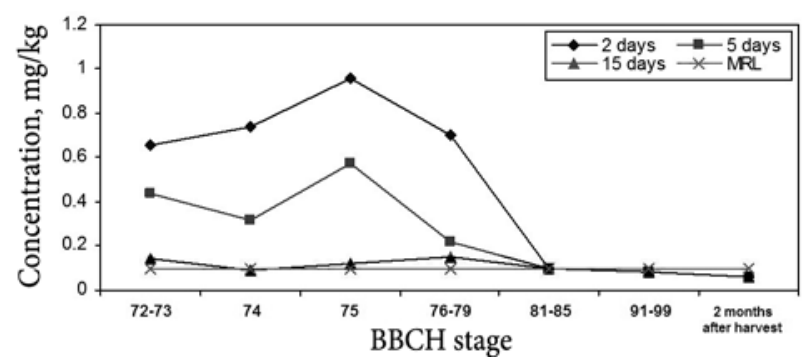

Fig. 12. Degradation of lambda-cyhalothrinin Jonathan apples

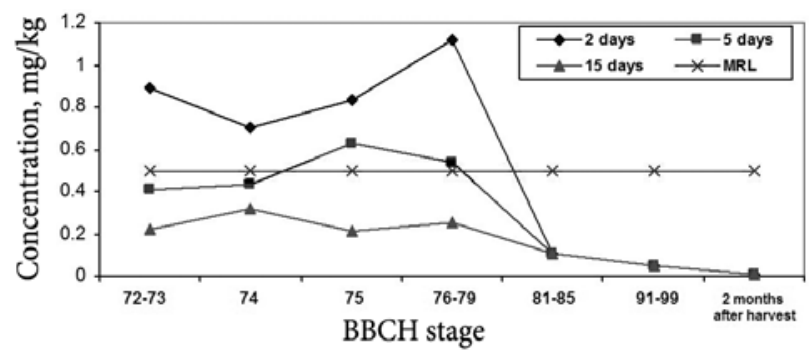

Fig. 13. Degradation of chlorpyrifos-methyl in Jonathan apples

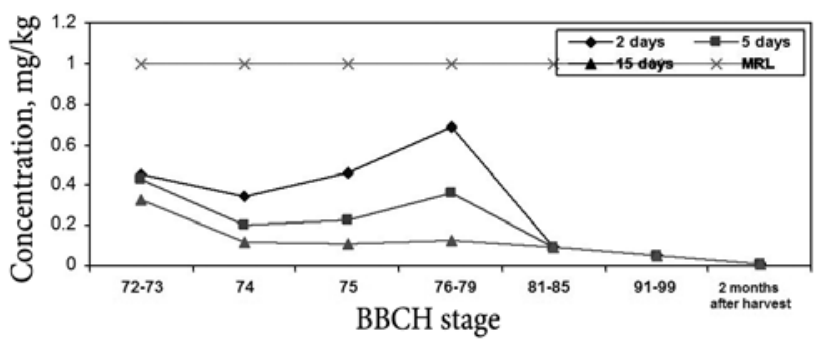

Fig. 14. Degradation of alpha-cypermethrin in Jonathan apples

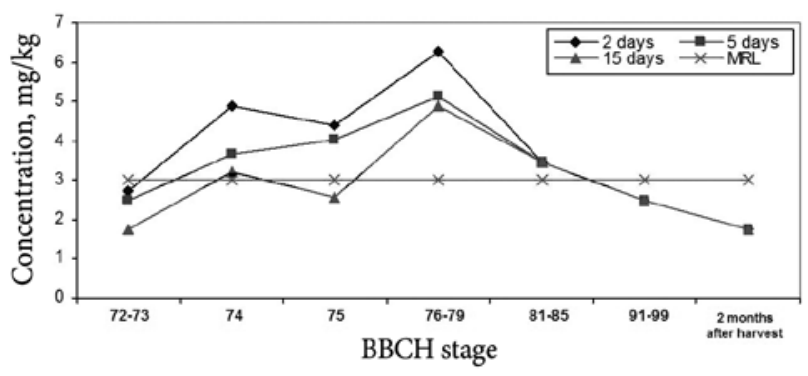

Fig. 15. Degradation of propagite in Jonathan apples observed for the first three stages of fruits development (BBCH 72-73, BBCH 74 and $\mathrm{BBCH} 75$ ), while the residual concentration of folpet was found below the MRL (Fig. 8). Upon ripening (BBCH 81-85), the folpet residuals reached a concentration of $2.59 \mathrm{mg} / \mathrm{kg}$, below the MRL (3 mg/kg).

Following the treatments with tebuconazole, the residuals concentration exceeded the MRL ( $1 \mathrm{mg} / \mathrm{kg})$ after 2, 5 and 15 days from the application of the treatment in apples in all phenological phases (Fig. 9). The degradation of tebuconazole is slow, because as a systemic fungicide a part of it remains on the surface of the fruits and another part penetrates inside, where it degrades in a time interval which can sometimes last up to a month.

The degradation of the captan depends on the time elapsed from the application of the treatment and the fall of the precipitations, while the temperature and the humidity have negligible effects (Xu et al. 2008), so that after 15 days from the application of the treatment in all fruit stages the residuals concentration was below the MRL ( $3 \mathrm{mg} / \mathrm{kg}$ ). Moreover, values much below the MRL were found 2 months after harvest (Fig. 10).

The degradation of the bifenthrin is influenced by the weather conditions as well, having a high volatilization tendency (Fig. 11). Upon harvesting, the residuals concentration was of $0.3 \mathrm{mg} / \mathrm{kg}$, reaching the MRL $(0.3 \mathrm{mg} / \mathrm{kg})$.

During the period 12.08.2011-17.08.2011 the degradation of the lambda-cyhalothrin through volatilization was extensively influenced by the very high values of temperature. After 15 days from the application of the treatment, a concentration of pesticide residuals of $0.12 \mathrm{mg} / \mathrm{kg}$ is reached, which is lower than the concentration of $0.7 \mathrm{mg} / \mathrm{kg}$ obtained after 2 days from application, for both the $2 / 3$ of normal size fruit (BBCH 76-79) and the fruit of normal size (BBCH $81-85)$. A drop of over $50 \%$ from the pesticide residuals content at 2 days after the application is also noticed within the period 15.07.2011-20.07.2011 (when the maximum temperatures were over $30^{\circ} \mathrm{C}$ as seen in Fig. 3 ).

It can be stated that the very high temperatures influenced the degradation of lambda-cyhalothrin in time, but not as much as the degradation of deltamethrin, which was performed especially due to the fabrication technology of the pesticide based on "zeon". In this case the incorporation of the ingredients in foams called "zeon", determines a longer action span than for a pyrethroid with a conventional formulation EC or WG type. The gradual release of the insecticide from the capsules determines the forming of a stable deposit, resistant to the action of the UV rays and to the precipitations. Upon harvesting, at 30 days after the last treatment the residual concentration was below the MRL, $0.1 \mathrm{mg} / \mathrm{kg}$ (Fig. 12).

Figure 13 shows a severe degradation of the chlorpyrifos-methyl in 15 days after the application of the treatment, following each phenological phase and reaching a residual concentration of $0.05 \mathrm{mg} / \mathrm{kg}$, much below MRL 
$(0.5 \mathrm{mg} / \mathrm{kg})$ at harvesting (BBCH 91-99). Also, in the period 15.07.2011-20.07.2011, the degradation of the chlorpyrifos-methyl through volatilization $(\log \mathrm{P}=4)$ was extremely influenced by high temperature values (as shown in Fig. 3), so that after 5 days from the treatment application, a residual concentration of $0.63 \mathrm{mg} / \mathrm{kg}$ chlorpyrifos-methyl was reached, while a concentration of $0.83 \mathrm{mg} /$ $\mathrm{kg}$ chlorpyrifos-methyl was found after 2 days following the treatment (Fig. 13).

The degradation of alpha-cypermethrin, which is a pyrethroid similar to deltamethrin and lambda-cyhalothrin, occurred gradually during 15 days after the treatment application (Fig. 14). In the ripening period $(\mathrm{BBCH}$ $81-85)$, the value of the pesticide residual deposit is below the MRL of $1 \mathrm{mg} / \mathrm{kg}$, and upon harvesting (BBCH 91-99) its concentration reaches $0.01 \mathrm{mg} / \mathrm{kg}$, a lot below the MRL.

In the case of the treatment with propargite, the residuals concentration in fruits with a size of $20-25 \mathrm{~mm}$ (BBCH 72-73) is $2.73 \mathrm{mg} / \mathrm{kg}$ after 2 days (Fig. 15), while the content obtained in the phenological phase of the $2 / 3$ normal size fruits (BBCH 76-79) is higher $(6.56 \mathrm{mg} / \mathrm{kg})$. The degradation of the propargite is slow in time, so that the residuals concentration decreased to $3.02 \mathrm{mg} / \mathrm{kg}$ at ripening (BBCH 81-85), which exceeds slightly the MRL ( $3 \mathrm{mg} / \mathrm{kg}$ ). In 2 months after harvesting, the concentration of propargite reached $1.77 \mathrm{mg} / \mathrm{kg}$, below the MRL, in the conditions of the apples storage in a dark room at a temperature of $4{ }^{\circ} \mathrm{C}$.

Due to high temperatures, the deltamethrin also suffers of severe volatilization. The value of the partition coefficient octanol/water $(\log \mathrm{P}>4$ ) and its big molecular mass, (505 u.a.m) also contribute to the deltamethrin degradation (Tomlin 2009), so that at harvesting (BBCH 9199), the value of the residual deltamethrin concentration reaches at $0.01 \mathrm{mg} / \mathrm{kg}$ and in two months after harvesting it is no longer detected (Fig. 16).
The triadimenol constitutes the second active substance of the product called Shavit F 72 WDG, used in the application of pesticide treatments in apples. The degradation of the triadimenol is emphasized after 15 days from the application of the treatment (Fig. 17), in two periods: 1) for a fruit of 30-40 $\mathrm{mm}(\mathrm{BBCH} 74)$; and 2) for a $1 / 2$ fruit from the normal size $(\mathrm{BBCH} 75)$, reaching a value below the MRL $(0.2 \mathrm{mg} / \mathrm{kg})$.

Weather conditions had a significantly influence on the triadimenol degradation. In the ripening period (BBCH 81-85), the residual concentration of triadimenol reached a value of $0.09 \mathrm{mg} / \mathrm{kg}$.

These analyses demonstrated that the treatments with various pesticides applied on Jonathan apples led to pesticides residues levels below the MRL. It was

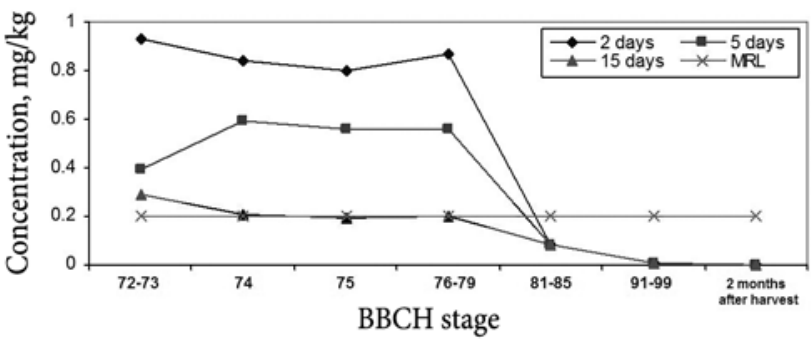

Fig. 16. Degradation of deltamethrin in Jonathan apples

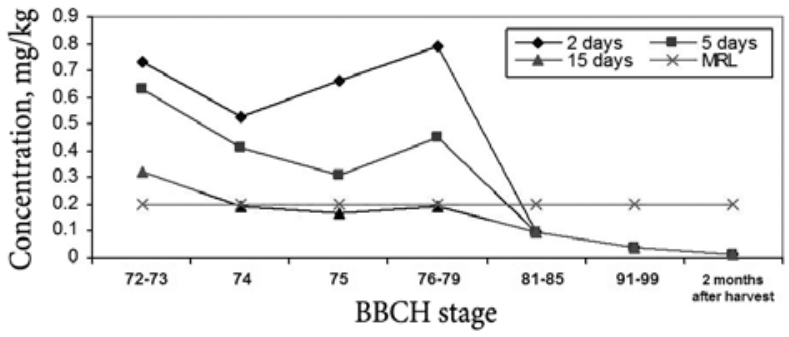

Fig. 17. Degradation of triadimenol in Jonathan apples

Table 4. Health risk estimation associated with pesticide residues in apples, at harvest

\begin{tabular}{|c|c|c|c|c|c|c|c|c|}
\hline \multirow[t]{2}{*}{ Pesticide } & \multirow{2}{*}{$\begin{array}{c}\text { Reference } \\
\text { dose } \\
\text { (mg/kg/day) }\end{array}$} & \multirow{2}{*}{$\begin{array}{c}\text { Concentration } \\
\text { of pesticides } \\
(\mathrm{mg} / \mathrm{kg})\end{array}$} & \multicolumn{2}{|c|}{$\begin{array}{c}\text { Estimated dose } \\
(\mathrm{mg} / \mathrm{kg} / \text { day })\end{array}$} & \multicolumn{2}{|c|}{ Hazard index } & \multicolumn{2}{|c|}{ Health risk } \\
\hline & & & Adults & Children & Adults & Children & Adults & Children \\
\hline Captan & 0.13 & 0.95 & $2.64 \times 10^{-3}$ & $5.88 \times 10^{-3}$ & 0.020 & 0.045 & No & No \\
\hline Folpet & 0.1 & 1.14 & $3.17 \times 10^{-3}$ & $7.06 \times 10^{-3}$ & 0.031 & 0.070 & No & No \\
\hline Triadimenol & $0.05^{*}$ & 0.04 & $1.11 \times 10^{-4}$ & $2.48 \times 10^{-4}$ & 0.002 & 0.004 & No & No \\
\hline Myclobutanil & $0.003^{*}$ & 0.1 & $2.78 \times 10^{-4}$ & $6.2 \times 10^{-4}$ & 0.092 & 0.206 & No & No \\
\hline Chlorothalonil & 0.015 & 1.15 & $3.20 \times 10^{-3}$ & $7.12 \times 10^{-3}$ & 0.213 & 0.475 & No & No \\
\hline Tebuconazole & $0.03^{*}$ & 1.06 & $2.95 \times 10^{-3}$ & $6.56 \times 10^{-3}$ & 0.098 & 0.218 & No & No \\
\hline Chlorpyrifos-methyl & $0.01^{*}$ & 0.05 & $1.39 \times 10^{-4}$ & $3.1 \times 10^{-4}$ & 0.013 & 0.030 & No & No \\
\hline Bifenthrin & 0.015 & 0.3 & $8.35 \times 10^{-4}$ & $1.85 \times 10^{-3}$ & 0.055 & 0.123 & No & No \\
\hline Alfa-cypermethrin & 0.01 & 0.05 & $1.39 \times 10^{-4}$ & $3.1 \times 10^{-4}$ & 0.013 & 0.030 & No & No \\
\hline Lambda-cyhalothrin & 0.005 & 0.08 & $2.23 \times 10^{-4}$ & $4.96 \times 10^{-4}$ & 0.044 & 0.099 & No & No \\
\hline Deltamethrin & $0.01^{*}$ & 0.01 & $2.78 \times 10^{-5}$ & $6.2 \times 10^{-5}$ & 0.002 & 0.006 & No & No \\
\hline Propargite & 0.02 & 2.47 & $6.87 \times 10^{-3}$ & $1.53 \times 10^{-2}$ & 0.343 & 0.765 & No & No \\
\hline
\end{tabular}


noticed that the pesticides from apples disappear quickly in the first days after the treatment application, so that an amount of up to $30-50 \%$ from the initial value is lost. Parts of these compounds are lost due to volatilization, but a part is absorbed in the shell and in the superficial layer of the fruit. After some time intervals (2, 5 or 15 days), the active substance reappears on the surface of the fruits, but disappears after a longer period of time. Repeated treatments (until five), with recommended dosages, were applied starting with the phenological phase of the fruit when its size was $20-25 \mathrm{~mm}$ till the normal size fruit. The detected residue levels were lower than those recommended by the European Union. The analyses showed that, at 30 days after the last treatment, the residual concentrations of pesticides were below MRL, except in the case of chlorothalonil and tebuconazole.

In the case of the myclobutanil, chlorothalonil, tebuconazole, parts of the residues remain at the surface of fruits, while other parts penetrate the fruits, where are degraded in an interval of time which can sometimes last up to a month.

\subsection{Estimation of health risk}

The health risk estimates associated with pesticide residues in apples, at harvesting time are summarized in Table 4. The table comprises reference daily dose and estimated dose for adults and children ( 6 to $<11$ years), as well as the corresponding hazard indices during the study period.

Results demonstrate that the exposure estimated dose values for each of the analysed pesticides do not exceed the RfDs, suggesting that risks to possible consumers are negligible. The hazard indices values which are $<1$ showed that the pesticides under study do not generate a health risk to human health, in spite of their presence in apples. The pesticide propargite, found at harvest in apples at a concentration of $2.47 \mathrm{mg} / \mathrm{kg}$, slightly below the MRL, is the only pesticide that if exceeds this value could pose a threat to children health considering that the resulted HI is equal to 0.765 .

\section{Conclusions}

1. The degradation of the pesticides in Jonathan apples is done in time, in a period of several months, according to the nature and structure of the pesticides applied. Overall, the pesticide regime gave residues levels much lower than those of the MRL, during the growth phases of apples.

2. Chlorothalonil and tebuconazole, upon harvesting have higher values than the MRL values. On the other hand, the products based on pyrethrum, such as, deltamethrin, chlorpyrifos-methyl, alpha-cypermethrin, lambda-cyhalothrin, upon harvesting, have a content of residuals a lot smaller than the MRL. The pesticides prepared under the form of emulsion (alpha-cypermethrin and deltametrin) volatilize faster compared with the ones prepared under the form of powders (captan, miclobuthanil), due to the thin layer of the pellicle. Even among the products in the form of emulsions there are differences regarding the degree of disappearance of the pesticides residues, according to the adhesive added, but also on the special formula, as in the case of lambda-cyhalothrin.

3. The degradation of the pesticides in apples is also determined by environmental conditions, such as temperature, precipitations, and humidity. If the environmental factors have high values immediately after spraying, it can lead to a significant drop in the content of the residuals in the first 2 , respectively 5 days from the application of the treatment.

4. The fruit phenological phase has also a high influence in the pesticide degradation. In the phenological phase corresponding to a fruit size of $20-25 \mathrm{~mm}$, the residuals of pesticides are higher than in the other phenological phases. The smaller fruits have a higher content of pesticide residues due to the reduced wax content in apple peel and to the thin shell which favourites the pesticides absorption.

5. Estimating the degradation of these substances is important for the estimation of the diet risks and in order to optimize the application of pesticides. The hazard indices values showed that the pesticides under study do not present a health risk to humans.

6. On the basis of the above findings, the results obtained in our study suggest the necessity for surveillance and monitoring programmes for pesticide residues in all food commodities in order to defend the final consumers from exposure to this kind of substances. Behaviour analysis of pesticides in fruits consists in a friendly approach which determines the production of fruits with no or minimal pesticide residues, in contrast to the conventional scheme where pesticide residues are not monitored.

\section{Acknowledgments}

This paper was elaborated with the support of a grant of the Romanian National Authority for Scientific Research, CNCS - UEFISCDI, project number PN-II-IDPCE-2011-3-0559", Contract 265/2011 and with the support of Plant Protection Agency Mureş, Romania.

\section{References}

Abhilash, P. C.; Singh, N. 2009. Pesticide use and application: An Indian scenario, Journal of Hazardous Materials 165(1-3): 1-12. http://dx.doi.org/10.1016/j.jhazmat.2008.10.061

Akoto, O.; Andoh, H.; Darko, G.; Eshun, K.; Osei-Fosu P. 2013. Health risk assessment of pesticides residue in maize and cowpea from Ejura, Ghana, Chemosphere 92(1): 67-73. http://dx.doi.org/10.1016/j.chemosphere.2013.02.057 
Barriada-Pereira, M.; Gonzalez-Castro, M. J.; Muniategui-Lorenzo, S.; Lopez-Mahia, P.; Prada-Rodriguez, D.; FernandezFernandez, E. 2005. Organochlorine pesticides accumulation and degradation products in vegetation samples of a contaminated area in Galicia (NW Spain), Chemosphere 58(11): 1571-1578.

http://dx.doi.org/10.1016/j.chemosphere.2004.10.016

Bempah, C. K.; Buah-Kwofie, A.; Denutsui, D.; Asomaning, J.; Tutu, A. O. 2011. Monitoring of pesticide residues in fruits and vegetables and related health risk assessment in Kumasi Metropolis, Ghana, Research Journal of Environmental and Earth Sciences 3: 761-771.

Claeys, W. L.; Jean-Francois, S.; Bragard, C.; Maghuin-Rogister, G.; Luc, P.; Schiffers, B. 2011. Exposure of several Belgian consumer groups to pesticide residues through fresh fruit and vegetable consumption, Food Control 22(3-4): 508-516. http://dx.doi.org/10.1016/j.foodcont.2010.09.037

Deng, Z. B.; Hu, J. Y.; Qin, D. M.; Li, H. 2010. Simultaneous analysis of hexaconazole, myclobutanil and tebuconazole residues in apples and soil by SPE clean up and GC with nitrogen-phosphorus detection, Chromatographia 71(7-8): 679-684. http://dx.doi.org/10.1365/s10337-010-1505-1

De Schampheleire, M.; Nuyttens, D.; Baetens, K.; Cornelis, W.; Gabriels, D.; Spanoghe, P. 2009. Effects on pesticide spray drift of the physicochemical properties of the spray liquid, Precision Agriculture 10(5): 409-420.

http://dx.doi.org/10.1007/s11119-008-9089-6

Dragus, A.; Beldean-Galea, M. S.; Mihaiescu, R.; Mihaiescu, T.; Ristoiu, R. 2012. Assessing impacts of triazine pesticides use in agriculture over the well water quality, Environmental Engineering and Management Journal 11: 319-323.

EFSA. 2013. The 2010 European Union Report on Pesticide Residues in Food, EFSA Journal 11: 3130 [online], [cited 04 February 2014]. Available from Internet: http://www.pan-europe.info/Issues/documents/Food/EFSA\%20monitoring\%20 residues\%202010\%20Mar\%2013.pdf

EURL-FV. 2010. Multiresidue Method using Mini-Luke followed by GC-QqQ-MS/MS for Fruits and Vegetables [online], [cited 04 February 2014]. Available from Internet: http://www.crlpesticides.eu/library/docs/fv/Validation_MiniLuke.pdf

Fernández-Cruz, M. L.; Barreda, M.; Villarroya, M.; Peruga, A.; Llanos, S.; García-Baudín, J. M. 2006. Captan and fenitrothion dissipation in field-treated cauliflowers and effect of household processing, Pest Management Science 62(7): 637-645. http://dx.doi.org/10.1002/ps.1217

FRESHFEL. 2013. Freshfel Consumption Monitor [online], [cited 04 February 2014]. Available from Internet: http://www. freshfel.org/docs/2013/Press_Releases/20130314_-_Consumption_Monitor_2012.pdf

Gericke, D.; Nekovar, J.; Hörold, C. 2010. Estimation of plant protection product application dates for environmental fate modeling based on phenological stages of crops, Journal of Environmental Science and Health, Part B: Pesticides, Food Contaminants, and Agricultural Wastes 45(7): 639-647. http://dx.doi.org/10.1080/03601234.2010.502433

Hlihor, R. M.; Apostol, L. C.; Smaranda, C.; Pavel, L. V.; Caliman, F. A.; Robu, B. M.; Gavrilescu, M. 2009. Bioavailability processes for contaminants in soils and their use in risk assessment, Environmental Engineering and Management Journal 8: 1199-1206.

Juraske, R.; Mutel, C.; Stoessel, F.; Hellweg, S. 2009. Life cycle human toxicity assessment of pesticides: comparing fruit and vegetable diets in Switzerland and the United States, Chemosphere 77(7): 939-945.

http://dx.doi.org/10.1016/j.chemosphere.2009.08.006

Kurz, M. H. S.; Goncalves, F. F.; Adaime, M. B.; da Costa, I. F. D.; Primel, E. G.; Zanella, R. 2008. A gas chromatographic method for the determination of the fungicide chlorothalonil in tomatoes and cucumbers and its application to dissipation studies in experimental greenhouses, Journal of the Brazilian Chemical Society 19(6): 1129-1135.

http://dx.doi.org/10.1590/S0103-50532008000600012

Mansour, S. A.; Belal, M. H.; Abou-Arab, A. A. K.; Gad, M. F. 2009. Monitoring of pesticides and heavy metals in cucumber fruits produced from different farming systems, Chemosphere 75(5): 601-609. http://dx.doi.org/10.1016/j.chemosphere.2009.01.058

Meier, U.; Bleiholder, H.; Weber, E.; Feller, C.; Hess, M.; Wicke, H.; van den Boom, T.; Lancashire, P. D.; Buhr, L.; Hack, H.; Klose, R.; Stauss, R. 2001. BBCH Monograph Growth stages of mono-and dicotyledonous plants. 2nd edition. Federal Biological Research Centre for Agriculture and Forestry. $158 \mathrm{p}$.

Mocanu, A. M.; Luca, C.; Odochian, L.; Zaharia, C.; Iordache, C. 2012. Assessment of the environmental impact of some new aryloxyalkyl carboxilic acid derivatives applied as plant protection compounds, Environmental Engineering and Management Journal 11: 1697-1706.

Osman, K. A.; Al-Humaid, A. M.; Al-Rehiayani, S. M.; AlRedhaiman, K. N. 2010. Monitoring of pesticide residues in vegetables marketed in Al-Qassim region, Saudi Arabia, Ecotoxicology and Environmental Safety 73(6): 1433-1439. http://dx.doi.org/10.1016/j.ecoenv.2010.05.020

Pogăcean, M. O.; Hlihor, R. M.; Preda, C.; Gavrilescu, M. 2013. Humans in the environment: comparative analysis and assessment of pesticide residues from field-grown tomatoes, European Journal of Science and Theology 9: 79-95.

Preda, C.; Ungureanu, M. C.; Vulpoi, C. 2012. Endocrine disruptors in the environment and their impact on human health, Environmental Engineering and Management Journal 11: 1697-1706.

Reinhold, K.; Tint, P. 2010. Hazard profile in manufacturing: Determination of risk levels towards enhancing the workplace safety, Journal of Environmental Engineering and Landscape Management 17(2): 69-80.

http://dx.doi.org/10.3846/1648-6897.2009.17.69-80

Salghi, R.; Luis, G.; Rubio, C.; Hormatallah, A.; Bazzi, L.; Gutierrez, A. J.; Hardisson A. 2012. Pesticide residues in tomatoes from greenhouses in Souss Massa Valley, Morocco, Bulletin of Environmental Contamination and Toxicology 88(3): 358-361. http://dx.doi.org/10.1007/s00128-011-0503-9

Schirra, M.; D’Aquino, S.; Cabras, P.; Angioni, A. 2011. Control of postharvest diseases of fruit by heat and fungicides: efficacy, residue levels, and residue persistence. A review, Journal of Agricultural and Food Chemistry 59(16): 8531-8542. http://dx.doi.org/10.1021/jf201899t

Soceanu, A. D.; Dobrinas, S.; Popescu, V.; Stanciu, G.; Epure, D. T. 2012. OCPs and PAHs distribution indifferent stages of tomato growing, Environmental Engineering and Management Journal 11: 457-462.

Tixier, P.; Chabrier, C.; Malézieux, E. 2007. Pesticide residues in heterogeneous plant populations, a model-based approach applied to nematicides in banana (Musa spp.), Journal of Agricultural and Food Chemistry 55(6): 2504-2508. http://dx.doi.org/10.1021/jf062710f 
Tomlin, C. D. S. (Ed.) 2009. The Pesticide Manual, a world compendium. 15th Edition. Alton: British Crop Protection Council. 1457 p.

Tucker, A. J. 2008. Pesticides residues in food - Quantifying risk and protecting the consumer, Trends in Food Science \& Technology 19(Supplement 1): S40-S55.

http://dx.doi.org/10.1016/j.tifs.2008.07.010

USEPA. 2011. Exposure Factors Handbook. 2011 Edition. National Center for Environmental Assessment Office of Research and Development U.S. Environmental Protection Agency Washington, DC 20460.

USEPA. 2013. Integrated Risk Information System (IRIS) [online], [cited 04 February 2014]. Available from Internet: http://cfpub.epa.gov/ncea/iris/index.cfm?fuseaction=iris.showSubstanceList

Van Klaveren, J. D.; Boon, P. E. 2009. Probabilistic risk assessment of dietary exposure to single and multiple pesticide residues or contaminants: summary of the work performed within the SAFE FOODS project, Food and Chemical Toxicology 47(12): 2879-2882. http://dx.doi.org/10.1016/j.fct.2009.10.047

Walpole, S. C.; Prieto-Merino, D.; Edwards, P.; Cleland, J.; Stevens, G.; Roberts, I. 2012. The weight of nations: an estimation of adult human biomass, BMC Public Health 12: 439. http://dx.doi.org/10.1186/1471-2458-12-439

Williamson, S.; Ball, A.; Pretty, J. 2008. Trends in pesticide use and drivers for safer pest management in four African countries, Crop Protection 27(10): 1327-1334.

http://dx.doi.org/10.1016/j.cropro.2008.04.006
Weinberg, B.; Teodosiu, C. 2012. Monitoring and assessment of herbicides removal by industrial wastewater treatment, Environmental Engineering and Management Journal 11: 215-224.

Winter, C. K.; Katz, J. M. 2011. Dietary exposure to pesticide residues from commodities alleged to contain the highest contamination levels, Journal of Toxicology 2011: 1-7. http://dx.doi.org/10.1155/2011/589674

WHO. 2003. GEMS/food regional diets. Regional per capita consumption of raw and semi-processed agricultural commodities [online], [cited 04 February 2014]. Available from Internet: http://www.who.int/foodsafety/publications/chem/regional_ diets/en/

Zhang, Z.-Y.; Liu, X.-J.; Yu, X.-Y.; Zhang, C.-Z.; Hong, X.-Y. 2007. Pesticide residues in the spring cabbage (Brassica oleracea L. var. capitata) grown in open field, Food Control 18(6): 723-730. http://dx.doi.org/10.1016/j.foodcont.2006.04.001

Zawiyah, S.; Che Man, Y. B.; Nazimah, S. A. H.; Chin, C. K.; Tsukamoto, I.; Hamanyza, A. H.; Norhaizan, I. 2007. Determination of organochlorine and pyrethroid pesticides in fruit and vegetables using SAX/PSA clean-up column, Food Chemistry 102(1): 98-103. http://dx.doi.org/10.1016/j.foodchem.2006.05.003

Xu, X. M.; Murray, R. A.; Salazar, J. D.; Hyder, K. 2008. The effects of temperature, humidity and rainfall on captan decline on apple leaves and fruit in controlled environment conditions, Pest Management Science Journal 64(3): 296-307. http://dx.doi.org/10.1002/ps.1520

Manuela Olga POGĂCEAN. Dr, Researcher at Plant Protection Agency Mureş (Romania). PhD in Chemical Engineering since 2013 from Gheorghe Asachi Technical University of Iasi, Romania. Research interests: plant protection, environmental risk assessment and management, pesticides degradation in fruits and vegetables.

Raluca-Maria HLIHOR. Dr, Researcher at Gheorghe Asachi Technical University of Iasi. PhD (Chemical Engineering 2011), Master's degree (Environmental Engineering and Management 2009), Bachelor's degree (Environmental Engineering 2008), all from Gheorghe Asachi Technical University of Iasi, Romania. Research interests: biosorption and bioaccumulation of persistent pollutants from aqueous solutions, bioremediation of soils polluted with persistent pollutants, human health risk assessment, pesticides degradation in fruits and vegetables.

Maria GAVRILESCU. Professor at the Department of Environmental Engineering and Management of the "Gheorghe Asachi" Technical University of Iasi, Romania, where she teaches courses in Chemical and Biological Process Engineering, Process Synthesis and Analysis, Integrated Pollution Prevention and Control, Sustainable Industrial Production and Environmental Risk Assessment and Management. She has published numerous books and articles in the fields of chemical and environmental engineering, pharmaceutical and environmental biotechnology, pollution prevention and cleaner production, risk assessment and management, which include over 400 titles. 